\title{
Primary systemic amyloidosis as a real diagnostic challenge - case study
}

\author{
SONIA JERZYKOWSKA ${ }^{1}$, MACIEJ CYMERYS ${ }^{1}$, LIDIA A. GIL ${ }^{2}$, ANDRZEJ BALCERZAK ${ }^{2}$, \\ DANUTA PUPEK-MUSIALIK', MIECZYSEAW A. KOMARNICKI ${ }^{2}$
}

'Department of Internal Medicine, Metabolic Diseases and Arterial Hypertension, Poznan University of Medical Sciences, Poland ${ }^{2}$ Department of Haematology, Poznan University of Medical Sciences, Poland

\begin{abstract}
Primary amyloidosis $(A L)$ is a rare variety of plasma cell dyscrasia, the diagnosis of which is often difficult to establish. Pathogenesis of amyloidosis involves extracellular deposition of insoluble protein fibrils in tissues, leading to insufficiency of affected organs. According to various sources, mean survival rate of patients with primary amyloidosis ranges from 12 to 24 months, making primary amyloidosis a disease with a very poor prognosis. Survival rate is significantly lowered in case of cardiac manifestation of amyloidosis (about 6 months survival in untreated patients). In recent years a considerable progress in AL treatment has been observed. Nowadays we are able not only to delay progression of amyloidosis, but also to improve the function of the affected organs. Unfortunately as first signs and symptoms of AL are usually nonspecific, the diagnosis of AL is often delayed, resulting in late introduction of optimal therapy. There are many diagnostic tests which can be used in diagnostic process of amyloidosis, i.e. electrophoresis, serum and urine immunofixation or affected organs and bone marrow biopsy. On establishing the diagnosis in a patient with suspected amyloidosis it should be remembered that particular diagnostic methods vary considerably in sensitivity.

The aim of this paper is to present a case report of a 27-year-old patient with primary amyloidosis focusing on diagnostic aspect of this condition. On the basis of this case, the authors would like to emphasize the value of precise diagnostic process, with immunological techniques playing undoubtedly a crucial role.
\end{abstract}

Key words: AL amyloidosis, Congo red stain, bone marrow trepanobiopsy, immunofixation.

(Centr Eur J Immunol 2014; 39 (1): 61-66)

\section{Introduction}

The amyloidosis constitutes a group of diseases related to deposition of insoluble protein fibers in various soft tissues. Amyloid deposits disrupt tissue structure and therefore inevitably lead to failure of the affected organ. There are several features that all amyloidogenic proteins share: $\beta$-pleated sheet configuration, acidophilia (in H\&E staining), metachromasy upon methylene blue staining during examination under light microscopy and characteristic apple-green birefringence under polarized light after Congo red staining $[1,2]$.

Amyloid can be found in almost any tissue, but in particular patients the distribution of amyloid deposits may vary. A localized form of amyloidosis is identified when amyloid fibrils are found only in a single organ. On the other hand, systemic amyloidosis involves several organs of the human body [3].

Some types of amyloidosis can run in families. These hereditary forms of the disease are related to genes muta- tions affecting amyloid precursor protein production and promoting the formation of insoluble amyloid fibrils [4].

The recommended classification of amyloidosis is based on the type of the amyloid precursor protein. So far, at least 30 human proteins have been identified as being amyloid precursors [5]. According to that classification, amyloidosis can be described by the use of the abbreviation "A+ suffix" where A stands for "Amyloid" and suffix indicates the specific amyloidogenic precursor [6].

AL amyloidosis is plasma cell dyscrasia - a disorder associated with the presence of malignant proliferation of plasma cells secreting monoclonal protein. In the case of AL amyloidosis, clonal population of plasma cells produces monoclonal immunoglobulin light chains or their fragments, which deposited in various tissues, become an amyloidogenic precursor [7].

AL amyloidosis is a rare disease, nevertheless, it is the most commonly diagnosed form of systemic amyloidosis. In the UK and the USA, the incidence of AL amyloidosis is about 6-10 cases per million population per year [8].

Correspondence: Maciej Cymerys, Department of Internal Medicine, Metabolic Diseases and Arterial Hypertension, Poznan University of Medical Sciences, Szamarzewskiego 84, Poznan, Poland, e-mail: maciejcymerys@wp.pl 
Regarding no updated epidemiological data for the Polish population, applying extrapolation of amyloidosis incidence in the UK population, Jędrzejczak estimates that annually in Poland approximately 250 new patients with AL amyloidosis may be detected [9]. Majority of new diagnoses is made in the elderly - in the USA, patients over 50 years of age comprise about $90 \%$ of the affected population, while in the UK, $66 \%$ of $\mathrm{AL}$ amyloidosis cases are found in patients between 50 and 70 years of age $[9,10]$. AL amyloidosis in men is twice as common as in women [11].

General symptoms of amyloidosis are usually nonspecific (the prevailing ones are general fatigue, weight loss and edema). The range of other symptoms depends on specific distribution of amyloid in a particular patient, resulting in impairment of affected tissues and organs. The most frequent syndromes observed in the course of amyloidosis are heart failure, nephrotic syndrome, hepatomegaly and peripheral neuropathy [10]. At the moment of establishing the diagnosis, over $60 \%$ of patients have at least two organs involved. The accumulation of amyloid proteins in the heart as well as in more than two organs is associated with poor prognosis [12].

A large variety of possible symptoms and wide range of their compilation impose an assumption that the most important step in the diagnostic process of amyloidosis is to raise the suspicion of this disorder [13]. Suspicion of amyloidosis should be a trigger factor for initiation of the proper diagnostic pathway leading to as precise diagnosis as possible. It is worth emphasizing that thanks to numerous researches concerning amyloidosis treatment conducted in last decades, we are able to delay progression of this disease more and more effectively. The essential factor, which determines achieving the satisfying therapeutic results is early onset of well-targeted therapy. It is extremely important to remember that treatment options for AL and other types of amyloidosis differ remarkably, i.e. the patient with AL amyloidosis can benefit from autologous hematopoietic cell transplantation, which is not considered as a therapeutic option in other types of amyloidosis [14].

According to presented information, it seems to be beyond any doubt that immunological diagnostic tests play a vital role in putting the proper diagnosis. Immunological tests not only are characterized by high sensitivity in amyloidosis recognition, but also allow one to differentiate AL amyloidosis from other types of this condition.

\section{Case report}

A 27-year-old Caucasian woman was admitted to the Department of Internal Diseases, Metabolic Disorders and Hypertension with the presumptive diagnosis of storage disease. This initial diagnosis had been made in a district hospital, where the patient had been referred due to general fatigue, epigastric pain, nausea, swelling of the lower limbs and increased abdominal girth. The results of per- formed examination had revealed hepatosplenomegaly, enlarged kidneys, hypertrophic cardiomyopathy and features of the nephrotic syndrome. The family history of the patient had been found remarkable since her mother had died of unrecognized reason at the age of 28.

On admission to our hospital the general condition of the patient was described as stable. She was aware and cooperating. On the physical examination the skin was remarkably pale, there was mild swelling around the ankles, on auscultation of the heart systolic murmur was heard, the liver was palpable with tenderness below the right costal margin.

Initial laboratory tests showed an increased value of erythrocyte sedimentation rate (ESR) $(70 \mathrm{~mm} / \mathrm{hr})$ with a normal C-reactive protein (CRP) $(1.0 \mathrm{mg} / \mathrm{l})$. The only abnormality in blood count was a slightly elevated platelet count $\left(449 \times 10^{9} / 1\right)$. There were elevated D-Dimer $(2315$ $\mathrm{ng} / \mathrm{ml})$ and fibrinogen $(474 \mathrm{mg} / \mathrm{dl})$ levels. Markers of iron homeostasis were also assessed - low levels of iron $(7.0 \mu \mathrm{mol} / \mathrm{l})$ and total iron binding capacity (TIBC) (31.9 $\mu \mathrm{mol} / \mathrm{l})$ were followed by a normal level of serum ferritin $(21.7 \mathrm{ng} / \mathrm{ml})$. Liver tests were suggestive of cholestasis, which was marked by elevation of alkaline phosphatase (292 IU/l) and $\gamma$-glutamyl transferase (GGTP) (457 IU/l), aminotranspherase activity, bilirubin level, as well as $\alpha$-amylase level were within the normal limits. The abnormalities in the lipid profile were revealed - the total cholesterol value was $22.54 \mathrm{mmol} / \mathrm{l}$, LDL-cholesterol $17.35 \mathrm{mmol} / \mathrm{l}$ and triglycerides $-3.87 \mathrm{mmol} / \mathrm{l}$. $N$-terminal prohormone of brain natriuretic peptide (NT-proBNP) reached the level of $2068.0 \mathrm{pg} / \mathrm{ml}$. Kidney function tests, that is serum creatinine concentration and blood urea nitrogen (BUN) were at the normal level (59 $\mu \mathrm{mol} / \mathrm{l}$ and 2.5 $\mathrm{mmol} / \mathrm{l}$, respectively), while in 24-hour urine collection, nephrotic range proteinuria of $5.9 \mathrm{~g} / \mathrm{l}$ occurred. Hepatitis type $\mathrm{B}$ and $\mathrm{C}$ were excluded by serology tests (hepatitis B surface antigen and anti-hepatitis $C$ virus antibodies were negative).

Serum protein electrophoresis revealed a decreased concentration of total protein (38.0 g/l), albumins (36.23\%) and $\gamma$-globulins $(9.5 \%)$ and increased concentration of $\alpha 2$-globulins (30.9\%) and $\beta 1$-globulins (15.71\%). Albumin/Globulin Ratio was low -0.6 . The concentration of serum $\kappa$ and $\lambda$ chains and free light chains was normal, with a normal $\kappa / \lambda$ ratio of 0.34 . Serum and urine immunofixation were performed and no monoclonal protein was detected.

Images obtained during ultrasound examination of the abdomen demonstrated increased echogenicity of the apparently enlarged liver - up to $17 \mathrm{~cm}$ in the midclavicular line and $28 \mathrm{~cm}$ in the mid-hepatic line. Other abnormal findings in the abdominal ultrasound included an increased diameter of the portal vein, the spleen enlargement $(14 \mathrm{~cm}$ of diameter) and the kidneys enlargement (without hydronephrosis). The size of pancreas was normal, but pan- 

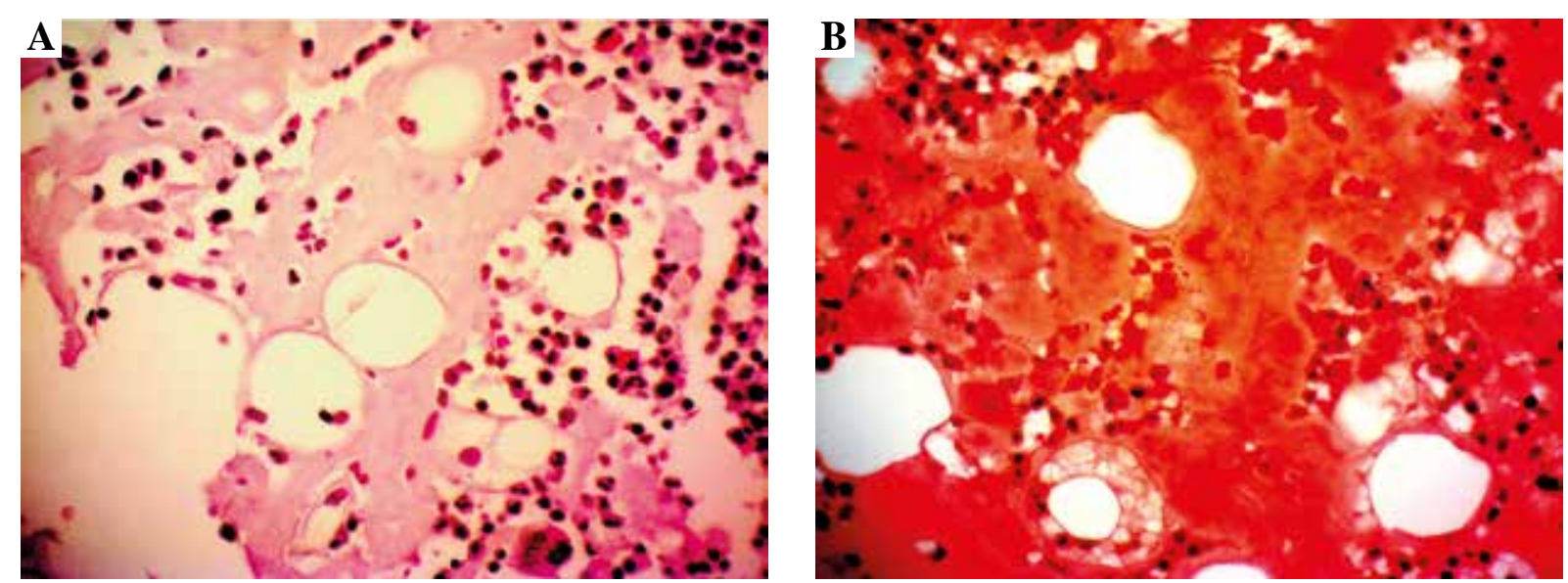

Fig. 1. 27-year-old woman with AL amyloidosis - bone marrow trepanobiopsy. A) Hematoxylin and eosin staining - homogenous amyloid masses in the bone marrow. B) Congo red staining - amyloid stains an orange red. (Courtesy of Prof. Mieczysław Komarnicki MD, PhD)

creatic tissue was described as hypoechoic and granular. Between distended loops of the intestines free fluid was detected. Fluid was also observed in the pouch of Douglas and both iliac fossae.

Electrocardiogram showed sinus tachycardia (100/ min), low voltage QRS complexes in the limb leads, small R-wave in leads III, aVF, V2, V3 and flat T-wave in leads I, aVL, V5 and V6.

The echocardiographic study disclosed concentric left ventricular thickening (interventricular septum and posterior wall thickness were 17 and $18 \mathrm{~mm}$, respectively) with the elevated left ventricular filling pressure and ejection fraction of $65 \%$. Moreover, a small amount of excessive pericardial fluid was detected.

Cardiac magnetic resonance imaging (MRI) was also performed. MR images analysis confirmed concentric left ventricular thickening as well as thickening of the right ventricular walls. No signs of myocardial perfusion defects were observed. Myocardial viability assessment was obtained using the Late Contrast Enhancement technique. Late enhancement observed in both left and right ventricles was interpreted as suggestive of the presence of amyloid infiltration in the patient's myocardium.

Following analysis of all available information concerning our patient, tentative diagnosis of AL amyloidosis was made. The aim of further investigation was to confirm the diagnosis of amyloidosis and to make it explicit through determining the composition of amyloid deposits. Nevertheless, there were two elements in the history of our patient which were still raising doubts about such diagnosis - onset of the disease at a young age, which is unusual for AL amyloidosis and unexplained early death of the patient's mother. Thus, before the final conclusion was reached, broad differential diagnostic procedures were performed to exclude other conditions of similar clinical manifestation. In differential diagnosis, rare storage diseases and systemic connective tissue disorders were taken into consideration.

Urinary excretion of glycosaminoglycans (GAG) was measured using DBM method - GAG excretion expressed as a GAG/creatinine ratio was $10.92 \mathrm{mg} / \mathrm{mmol}$ (reference values for individuals aged over 20 years - 2.95-4.87 mg/ $\mathrm{mmol})$. According to the literature, in the case of renal amyloidosis, a decrease in urinary glycosaminoglycans excretion is observed [15]. Excessive GAG excretion was the reason for further observation towards storage diseases in our patient. Laboratory investigation performed in the Metabolic Laboratory in the Department of Pediatrics and Institute of Clinical Chemistry of Hamburg University Medical Center with high probability excluded the presence of Fabry's disease, as well as Pompe disease, Gaucher's disease, type A and B of Niemann-Pick disease and MPS I (mucopolysaccharidosis type I) and MPS VI (mucopolysaccharidosis type VI).

As a conclusion of the rheumatologic consultation, tests for anti-neutrophil cytoplasmic antibodies were carried out - both c-ANCA (cytoplasmic anti-neutrophil cytoplasmic antibodies) and p-ANCA (perinuclear anti-neutrophil cytoplasmic antibodies) were negative. Negative were particularly the antibodies against proteinase 3, myeloperoxidase, lactoferrin, cathepsin and bacterial permeability increasing factor. Tests for ANA (antinuclear antibodies) and anti-GBM (anti-glomerular basement membrane) antibodies were also negative.

In order to confirm the diagnosis of amyloidosis, a biopsy of rectal mucosa was taken. The obtained histological material contained single amorphous deposits in mucosa and blood vessel walls of the rectum and was tested positive with Congo red, thereby maintaining suspicion of amyloidosis. Nevertheless, further histochemical tests 
could not be performed as a result of insufficient amount of tissue gained from the biopsy, what is not infrequently encountered diagnostic problem [16].

Subcutaneous abdominal fat biopsy was also performed, however no deposits of amyloid were found in the specimen.

Bone marrow biopsy with following Congo red staining and immunohistochemical analysis were done (Fig. 1). The specimen stained with Congo red dye revealed large amounts of amyloid disturbing normal structure of the bone marrow. Immunohistochemical analysis strongly suggested the presence of monoclonal plasma cells, reaching almost $10 \%$. These results were confirmed in the amyloidosis reference centre - National Amyloidosis Centre UCL Division of Medicine in London, where the diagnosis was specified by performing immunohistochemistry with monospecific antibodies against serum amyloid A (SAA), transthyretin, $\kappa$ and $\lambda$ immunoglobulin light chains. Positive reaction was obtained for $\lambda$ immunoglobulin light chains. During examination under polarized light the specimen demonstrated green birefringence characteristic of amyloid fibrils. These findings were fundamental for establishing the final diagnosis of AL- $\lambda$ subtype amyloidosis.

During hospitalization our patient was putting on weight, abdominal girth was also increasing. These signs were reflected in the findings of abdominal ultrasonography revealing a gradually collecting amount of fluid in the patient's abdomen. Increase in NT-proBNP concentration was observed. It was $4688.0 \mathrm{pg} / \mathrm{ml}$ on the seventeenth day of hospitalization and six days later it reached the level of $5036 \mathrm{pg} / \mathrm{ml}$, which was two and a half as much as at the time of admission. While awaiting final immunohistochemical tests results, the patient's condition deteriorated - peripheral edema and ascites were expanding as a result of both the heart and kidney failure. Within a month, renal function parameters changed dramatically, creatinine concentration from the normal level $(104 \mu \mathrm{mol} / \mathrm{l})$ became considerably elevated $(466 \mu \mathrm{mol} / \mathrm{l})$. Creatinine clearance from the level of $66 \mathrm{ml} / \mathrm{min} / 1.73 \mathrm{~m}^{2}$ decreased to $14 \mathrm{ml} /$ $\min / 1.73 \mathrm{~m}^{2}$. Since that time the patient has required renal replacement therapy.

Immediately after receiving the results from the National Amyloidosis Centre UCL Division of Medicine the patient was admitted to the Hematology Division of our Hospital to undergo qualification of AL amyloidosis targeted chemotherapy. Autologous stem cell transplantation as the prospective therapeutic solution was also considered.

\section{Discussion}

Nearly eight months passed from the moment of our patient's admission to the district hospital to chemotherapy initiation. In spite of early made initial diagnosis, prompt therapy was delayed as a result of difficulties in diagnosis objectification. During all this time our patient's manage- ment was based on symptomatic treatment. The patient needed supportive care including the use of diuretics, angiotensin-converting enzyme inhibitors, antiemetics and antidepressants. It should be noted that the role of symptomatic treatment in patients suffering from amyloidosis cannot be neglected as it is crucial to prevent decompensation of organs affected by disease [17].

The main reason for which disease-directed therapy of amyloidosis is postponed until accurate amyloidogenic protein typing is performed, is high risk therapy applied in amyloidosis treatment. Taking into account that different types of systemic amyloidosis require diverse therapeutic approaches and that at the same time, regardless of the amyloidosis type, the recommended treatment is aggressive and often uses cytotoxic drugs, we reach a conclusion that treatment carrying such a high risk of serious side-effects should not be administered without definite indications $[18,19]$.

None of widely available laboratory tests using blood or urine samples, as well as none of imaging studies is specific enough to determine the certain diagnosis of amyloidosis independently of other examinations results [20, 21].

According to diagnostic criteria of the Mayo Clinic, to recognize systemic light-chain amyloidosis we need to reveal coexistence of the following findings:

- clinical symptoms resulting from amyloid infiltration of particular organs,

- positive result of amyloid Congo red staining in biopsy material containing amyloid deposits,

- evidence indicating that amyloid deposits contain immunoglobulin light chain proteins,

- confirmed presence of monoclonal plasma cell proliferative disorder.

It was estimated that about 2-3\% of patients suffering from AL amyloidosis do not meet above criteria of diagnosis [22].

According to literature data, in the case of a patient with clinically suspected AL amyloidosis, serum and urine immunofixation along with Ig-free light chain (FLC) assay should be used as screening tools [20]. Even in a half of cases, the classical gel electrophoresis can give false negative results, but its sensitivity increases to $80 \%$ with the use of immunofixation. This can be explained by a usually low serum concentration of monoclonal protein [10]. A small amount of monoclonal protein detected in amyloidosis patients' serum is, in turn, a consequence of a typically low percentage of plasma cells found in bone marrow in the course of AL amyloidosis (usually < 10\%) [12]. Sensitivity of circulating FLCs measurements reaches $98 \%$, nevertheless their specificity is low as they give false positive results in the case of other types of plasma cell dyscrasias [23]. In healthy individuals, prevalence of $\kappa$ light chains in bone marrow is observed, while in patients with AL amyloidosis $\kappa / \lambda$ FLC ratio 1:3 is a characteristic feature [24]. It is assumed that the normal value of $\kappa / \lambda$ ratio makes the 
diagnosis of AL-amyloidosis unlikely [20]. In our patient, despite the finally achieved definitive confirmation of AL amyloidosis, $\kappa / \lambda$ ratio measured during hospitalization was 0.34 with the reference of the normal range from 0.26 to 1.65. Considering the above mentioned figures, we incline to the statement that when strong clinical suspicion of amyloidosis appears, negative results of serum and urine protein immunofixation cannot imply neglecting further diagnostic procedure [20].

The next diagnostic step is tissue biopsy for amyloid protein investigation. Tissue samples usually undergo Congo red staining. Congo red dye is the most popular one applied to a tissue suspected of amyloid protein accumulation. It enables obtaining pathognomonic green birefringence of stained tissues examined under polarized light in the case of the presence of amyloid deposits in the tissue specimen [25]. The choice of biopsy site seems to be another essential issue. Theoretically, knowing which of the patient's organ is affected, we are able to use biopsy to get a tissue sample directly from the diseased organ expecting high reliability of such targeted biopsy procedure. Indeed, it has been estimated that amyloid accumulation can be visualized in more than $90 \%$ of liver or kidney biopsies taken from patients with AL amyloidosis. However, attention should be paid to the fact that biopsy of parenchymal organs poses in particular a risk of internal bleeding. Therefore, in the case of amyloidosis, with the patients' increased bleeding susceptibility [26], it seems to be reasonable to treat parenchyma organs biopsy rather as the procedure of last choice, which can be used when other, less invasive methods give equivocal results. A simple and safe method with a relatively high sensitivity $(60-80 \%)$ is the biopsy of subcutaneous fatty tissue. Biopsies of rectal mucosa and bone marrow are also often used, the sensitivity of these is $50-70 \%$ and $50-55 \%$, respectively [27]. The combination of both biopsy of the iliac crest bone marrow and abdominal fat pad fine needle aspiration gives positive results in $85 \%$ of cases [20]. In reference to our patient the results of her abdominal subcutaneous fat aspiration were negative and the interpretation of rectal mucosa biopsy uncertain, however bone marrow trepanobiopsy clearly indicated amyloid masses contained in bone marrow.

The last but not least stage of the diagnostic approach of AL amyloidosis is confirming the immunoglobulin light chain origin of amyloid fibrils. As it was mentioned at the beginning it is practically impossible to distinguish particular types of amyloidosis referring only to their clinical symptoms. In different therapeutic options dedicated to various types of amyloidosis, significance of identification of the protein forming amyloid fibrils is beyond any doubt. The presence of serum and urine immunoglobulin concentration or fractions abnormalities is not conclusive evidence of amyloid deposits origin and should not be treated as the factor excluding other types of amyloidosis than AL. Case reports of patients with two types of amyloi- dosis coexisting have been already described [28]. Another possibility is coexistence of monoclonal gammopathy of undetermined significance being a cause of the excessive amount of serum FLC and inherited amyloidosis with amyloidogenic protein completely different from immunoglobulin light chains [29]. It should be remembered that some cases of hereditary amyloidosis occur as a result of a new (de novo) mutation. It is generally supposed that a negative familial history is the factor leading to misdiagnosis of hereditary forms of amyloidosis and underestimation of its incidence [28,30]. Positive familial history of early death in our patient obligated us to be particularly carful in drawing any conclusions. We had to take into account a possibility of hereditary amyloidosis as being the only or coexisting with AL amyloidosis type of disease in our patient.

The tool used in identifying amyloid protein and thereby establishing the amyloidosis type, is immunohistochemistry [31]. The positive control for immunohistochemical tests is ensured by antisera to serum amyloid P (SAP) as SAP is a common constituent of all the types of amyloid deposits [32]. In routine immunohistochemical investigations, the tissue samples are incubated with specific antibodies directed against most popular amyloid precursors, such as $\kappa$ and $\lambda$ light chains, serum amyloid A and transthyretin [32]. In the presented case, immunohistochemical staining was the method which enabled establishing final diagnosis of AL amyloidosis $\lambda$ subtype.

It is worth mentioning that in recent years, apart from developing new therapeutic options, diagnostic techniques have been also improved. A more sophisticated diagnostic tool, so far used mainly for research, is immunogold electron microscopy (antibodies used in this assay are gold-labeled). Immunogold electron microscopy is derived from immunochemical tests, combining advantages of immunochemistry and electron microscopy [33]. Introduction of new diagnostic techniques are likely to revolutionize the diagnostic approach in the near future, among these laser microdissection and mass spectrometry-based proteomic analysis of biopsy material seem to be particularly promising [34]. Genetic testing plays the vital role in confirming most common hereditary forms of amyloidosis. Identifying the genetic mutation of the amyloid precursor proteins by the use of genetic tests remarkably contributes to establishing the correct diagnosis [29].

In summary, on account of the dynamic development of therapeutic procedures dedicated to amyloidosis management and wide availability of these advanced therapeutic options, early establishing of the most precise diagnosis with typing of amyloidogenic protein becomes more and more vital for achieving satisfactory results of implemented treatment. Unfortunately, unlike new treatment options for amyloidosis, accurate diagnosis is hard to reach. Taking into consideration the poor survival rate of untreated patients with amyloidosis, it appears that current efforts 
should be mainly focused on improving and popularizing diagnostic tools used in amyloid protein typing.

Authors declares no conflict of interest.

\section{References}

1. Zimmerman-Górska I: Choroby tkanki łącznej. In: Choroby wewnętrzne. Szczeklik A (eds.). Wydawnictwo Medycyna Praktyczna, Kraków 2010; 1819-1821.

2. Jurczyszyn A, Skotnicki AB (2004): Postępy w badaniach nad molekularną patogenezą amyloidozy oraz implikacje kliniczne. Adv Clin Exp Med 13: 669-676.

3. Glaudemans AWJM, Slart RHJA, Noordzij W, et al. (2013): Utility of 18F-FDG PET(/CT) in patients with systemic and localized amyloidosis. Eur J Nucl Med Mol Imaging 40: 1095-1101.

4. Benson MD, Liepnieks JJ, Yazaki M, et al. (2001): A new human hereditary amyloidosis: the result of a stop-codon mutation in the apolipoprotein AII gene. Genomics 72: 272-277.

5. Sipe JD, Benson MD, Buxbaum JN, et al. (2012): Amyloid fibril protein nomenclature: 2012 recommendations from the Nomenclature Committee of the International Society of Amyloidosis. Amyloid 19: 167-170.

6. Merlini G, Westermark P (2004): The systemic amyloidoses: clearer understanding of molecular mechanisms offers hope for more effective therapies. J Intern Med 255: 159-178.

7. Dmoszyńska A: Dyskrazje plazmocytowe. In: Hematologia. Dmoszyńska A (eds.) Wydawnictwo Medical Tribune Polska, Warszawa. 2011; 532-551.

8. Banypersad SM, Moon JC, Whelan C, et al. (2012): Updates in cardiac amyloidosis: a review. J Am Heart Assoc 1:e000364.

9. Jędrzejczak WW (2009): Zasady rozpoznawania i leczenia amyloidozy AL. Acta Haemat Pol 40: 363-367.

10. Żelichowski G, Lubas A, Wańkowicz Z (2008): Postępy diagnostyki i leczenia AL amyloidozy. Pol Merk Lek 142: 340-345.

11. Jamroziak K, Wnuk K, Iskierka E (2010): Terapia amyloidozy pierwotnej. Acta Haemat Pol 41: 423-432.

12. Gil L, Komarnicki M (2009): Rola transplantacji autologicznych komórek hematopoetycznych w leczeniu systemowej amyloidozy pierwotnej. Pol Merkuriusz Lek 27: 181-184.

13. Gillmore JD, Hawkins PN (2013): Pathophysiology and treatment of systemic amyloidosis. Nat Rev Nephrol 9: 574-586.

14. Gertz MA, Merlini G, Treon SP (2004): Amyloidosis and Waldenstrom's macroglobulinemia. Hematology Am Soc Hematol Educ Program 257-282.

15. Tencer J, Torffvit O, Grubb A, et al. (1997): Decreased excretion of urine glycosaminoglycans as marker in renal amyloidosis. Nephrol Dial Transplant 12: 1161-1166.

16. Picken MM (2010): Amyloidosis-where are we now and where are we heading? Arch Pathol Lab Med 134: 545-551.

17. Palladini G, Merlini G (2009): Current treatment of AL amyloidosis. Haematologica 94: 1044-1048.

18. Rosenzweig M, Landau H (2011): Light chain (AL) amyloidosis: update on diagnosis and management. J Hematol Oncol 4: 47.

19. Hazenberg BP, Van Gameren II, Bijzet J, et al. (2004): Diagnostic and therapeutic approach of systemic amyloidosis. Neth J Med 62: 121-128.
20. Gertz MA (2012): Immunoglobulin light chain amyloidosis: 2012 update in diagnosis, prognosis, and treatment. Am J Hematol 87: 183-189.

21. Palladini G, Russo P, Bosoni T, et al. (2009): Identification of amyloidogenic light chains requires the combination of serum-free light chain assay with immunofixation of serum and urine. Clin Chem 55: 499-504.

22. Rajkumar SV, Dispenzieri A, Kyle RA (2006): Monoclonal Gammopathy of Undetermined Significance, Waldenström Macroglobulinemia, AL Amyloidosis, and Related Plasma Cell Disorders: Diagnosis and Treatment. Mayo Clin Proc 81: 693-703.

23. Lachmann HJ, Gallimore JR, Gillmore JD, et al. (2003): Outcome in systemic AL amyloidosis in relation to changes in concentration of circulating immunoglobulin free light chains following chemotherapy. Br J Haematol 122: 78-84.

24. Sanchorawala V (2006): Light-Chain (AL) Amyloidosis: Diagnosis and Treatment. Clin J Am Soc Nephrol 1: 1331-1341.

25. Linke RP: Congo red staining of amyloid: improvements and practical guide for a more precise diagnosis of amyloid and the different amyloidoses. In: Protein reviews. Protein Misfolding, Aggregation, and Conformational Diseases. Uversky VN, Fink AL (eds.) Springer, New York 2006; 239-276.

26. Sucker C, Hetzel GR, Grabensee B, et al. (2006): Amyloidosis and bleeding: pathophysiology, diagnosis, and therapy. Am J Kidney Dis 47: 947-955.

27. Usnarska-Zubkiewicz L, Hołojda J, Kuliczkowski K (2011): AL Amyloidosis (Amyloidosis Antibody Light). Part 2 - Epidemiology, Clinical Symptoms, Diagnosis and Treatment of Amyloidosis AL. Adv Clin Exp Med 20: 771-788.

28. Comenzo RL, Zhou P, Fleisher M (2006): Seeking confidence in the diagnosis of systemic AL (Ig light-chain) amyloidosis: patients can have both monoclonal gammopathies and hereditary amyloid proteins. Blood 104: 3489-3491.

29. Lachmann HJ, Booth DR, Booth SE, et al. (2002): Misdiagnosis of hereditary amyloidosis as AL (primary) amyloidosis. N Engl J Med 346: 1786-1791.

30. Picken MM (2007): New insights into systemic amyloidosis: the importance of diagnosis of specific type. Curr Opin Nephrol and Hypertens 16: 196-203.

31. Schönland SO, Hegenbart U, Bochtler T, et al. (2012): Immunohistochemistry in the classification of systemic forms of amyloidosis: a systematic investigation of 117 patients. Blood 119: 488-493.

32. Gertz. MA (2004): The Classification and Typing of Amyloid Deposits. Am J Clin Pathol 121: 787-789.

33. Leung N, Nasr SH, Sethi S (2012): How I treat amyloidosis: the importance of accurate diagnosis and amyloid typing. Blood 120: 3206-3212.

34. Vrana JA, Gamez JD, Madden BJ (2009): Classification of amyloidosis by laser microdissection and mass spectrometry-based proteomic analysis in clinical biopsy specimens. Blood 114: 4957-4959. 